\title{
الوسائط المتعددة في تطوير نموذج تعليم اللغة العربية: \\ بحث في المدرسة العالية المحكومية كليمنتان الجنوبية
}

\author{
Faisal Mubarak \\ Fakultas Tarbiyah dan Keguruan IAIN Antasari \\ Jl. A. Yani, KM. 4,5 Banjarmasin, Kalimantan Selatan, 70235 \\ e-mail: mubarakseff1980@yahoo.com
}

\begin{abstract}
Abstrak: Peran Multimedia dalam Pengembangan Pembelajaran Bahasa Arab: Studi pada Madrasah Aliyah Negeri di Kalimantan Selatan. Bahasa Arab merupakan salah satu mata pelajaran yang wajib diajarkan di sekolah agama mulai dari tingkat dasar sampai perguruan tinggi. Lamanya waktu yang dipergunakan dalam mempelajari bahasa Arab tidak berbanding lurus dengan kemampuan yang memadai. Penelitian ini menggunakan pendekatan penelitian dan pengembangan yang dilakukan pada 3 (tiga) Madrasah Aliyah Negeri yang ada di tiga kabupaten/ kota di Kalimantan Selatan. Penulis mengemukakan bahwa faktor penyebab rendahnya kualitas kemampuan bahasa Arab siswa yang dilatarbelakangi oleh materi yang abstrak, dan tidak disampaikan dengan pendekatan, model, metode, serta media pembelajaran yang kongkrit dan praktikal, dan persepsi negatif bahwa bahasa Arab sulit dipelajari. Salah satu cara yang yang dapat dikembangkan adalah dengan mengubah sistem pembelajaran konvensional menjadi pembelajaran yang lebih efektif dan efisien dengan memanfaatkan multimedia.
\end{abstract}

Abstract: The Role of Multimedia in Developing Arabic Teaching Models: A Study on Islamic Senior High School in South Kalimantan. Arabic is one of the prerequisite subjects taught in Islamic learning institution from the lower to. The graduates are expected to have basic ability in Arabic language both spoken and written. However, student's still have some difficulties in learning Arabic. This research was conducted in three Islamic High Schools in the three districts in South Kalimantan. This study use an approach research and development. This study reveals some of aspects which influence the low quality of student in using Arabic, they are the abstract material, which are not delivered by appropriate approaches, models or methods, it is not also supported by more concrete, and practical media for teaching. In addition, there is negative percept among student that Arabic language was difficult and complicated to learn. To solve this problem, it's necessary to develop the concept learning system more effective and efficient by using multimedia.

Keywords: model pembelajaran, bahasa Arab, multimedia, Kalimantan Selatan 


\section{المقدمة}

تعد اللغة العربية من أغزة اللغات مادة وأطوعها في تأليف الجمل وصياغة العبارات، فهي

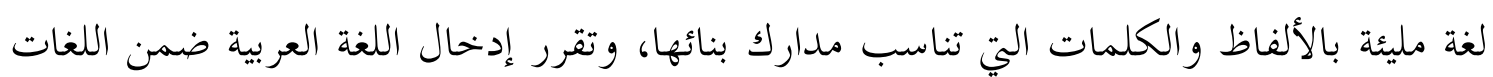

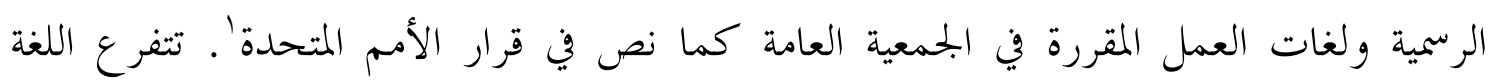

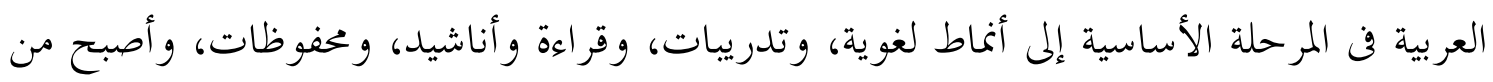





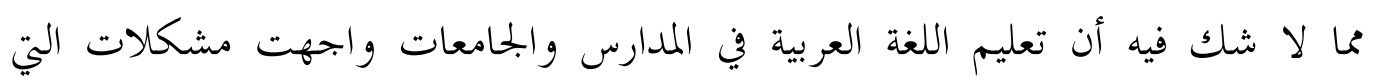
تعترض دون الوصول إلى الأهداف المرجوة، وهذه العقبات تتعلق بالجوانب الكثيرة منها ما يتعلق

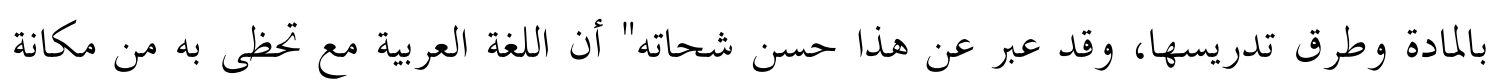

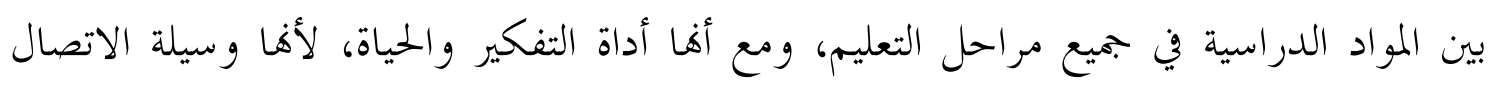

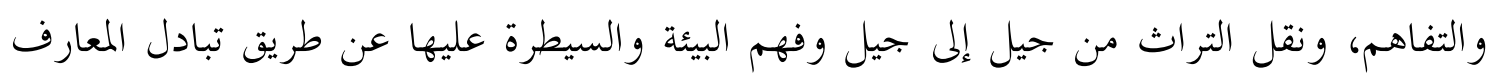

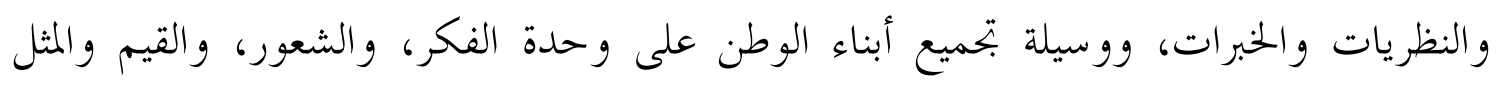

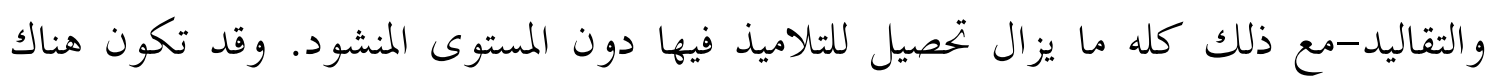

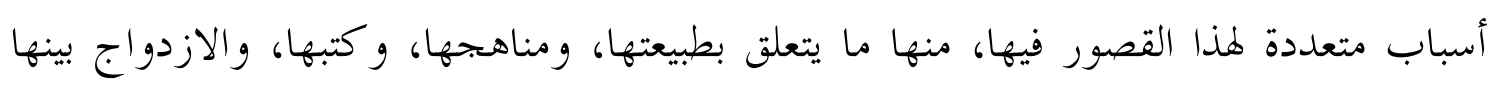

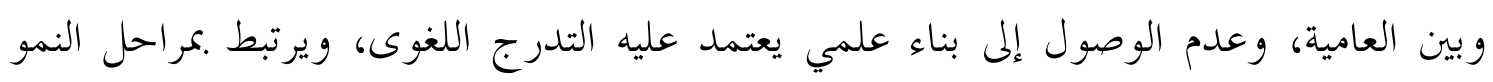
ارتباطا وثيقا. لكن من أهم الأسباب أيضا طرق تعليمها" '.




ما حصلوا رغم أهم قد درسوا طوال سنوات عديدة. والمدرس يعلمهم هذه اللغة النظريات

\footnotetext{
'بممود رشدي أحمد طعيمة، طرق تدربس اللغة العربية والتربية الدينية في ضوء الإتجهات الحلديثة (القاهرة: دار الحلب، r19A1)، ص. اOب r. كبعد الكريم، ملدى توافر مهارات تكنولجيا التعليم للدي معلمي اللغة العربية في المرحلة الأساسية (الأردن: دون المطبع، •. •r)، ص. r. rعبد الله أحمد، مذكرة في طرق تدريس اللغة العربية (الرياض: جامعة محمد بن سعود، بدون سنة الطباعة)، ص. r.
} 
والقواعد التي اعتبرها الطلابة أمر ممل، ومن جانب أخرى كفائة الطلبة في التكلم والتخاطب باللغة العربية لا زالت ضعيفة؛.

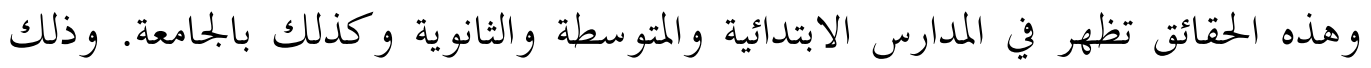

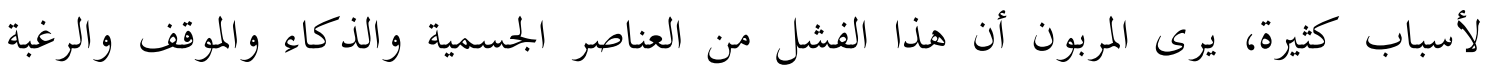

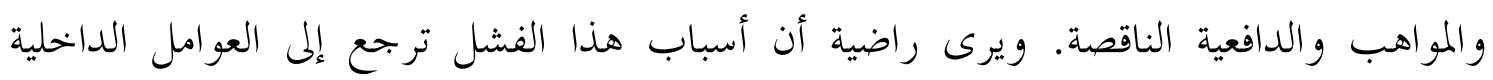

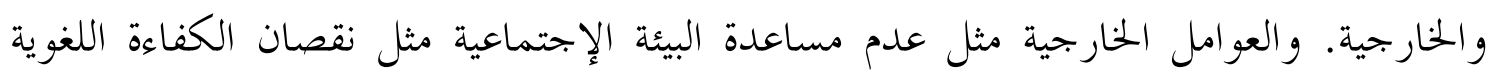

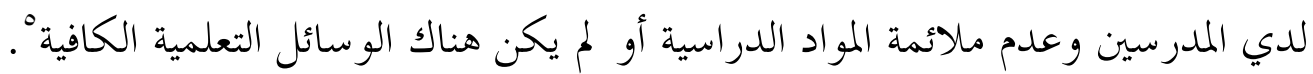

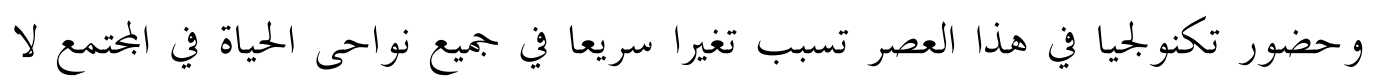

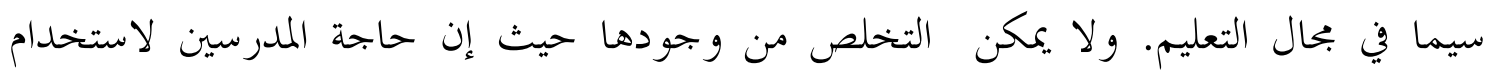

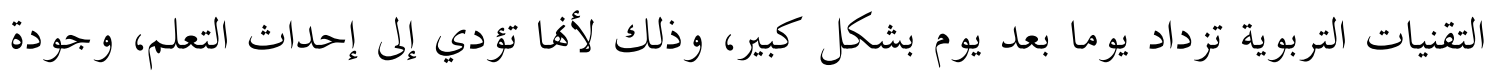

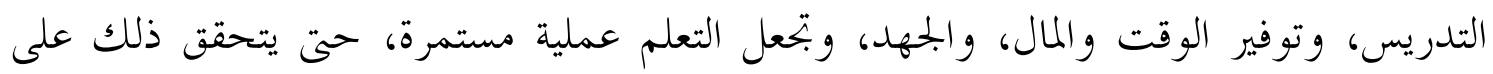

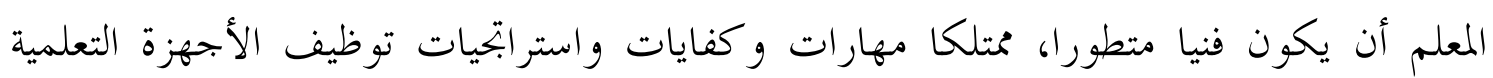
ومواردها، لمساعداته في بلوغ الأهداف التعلمية بدرجة من من الإتقان.



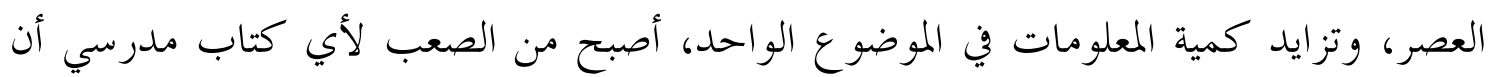

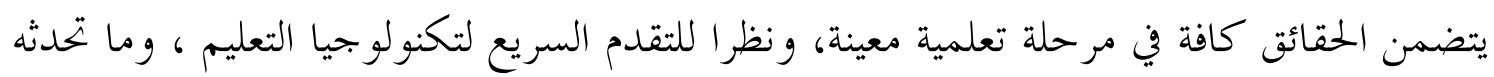

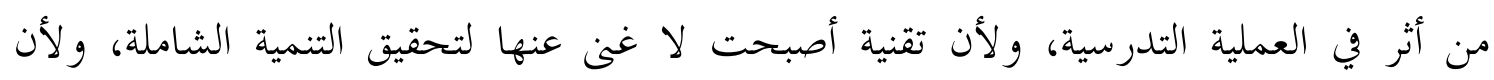
تحديث التعليم ينبغي أن ينطلق من قاعدة تطوير طرائق التدريس وأساليبه واسترابتياته، أصبح

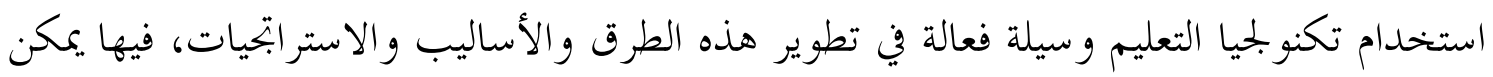
الإسهام في زيادة استيعاب الطلبة للمناهج الدراسية، وبذلك لا بد بد من الإهتمام بتطوير وسائل ولئل

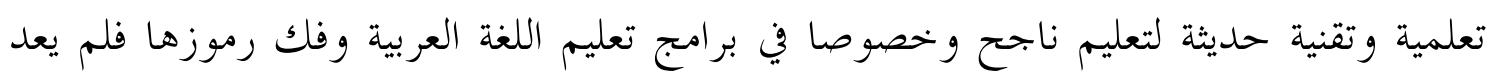
المعلم هو الوسيلة الوحيدة أو المصدر الوحيد للمعلومة.



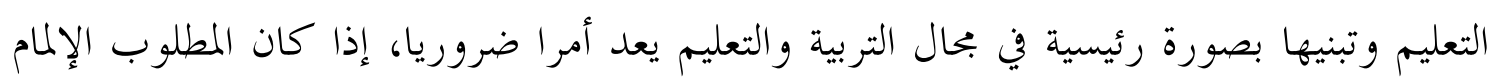

"نابيلا لو بيس، قاموس مخاطبة بالعامية (جاكرتا: ألو إإندونسيا، rا.r)، ص. 9.

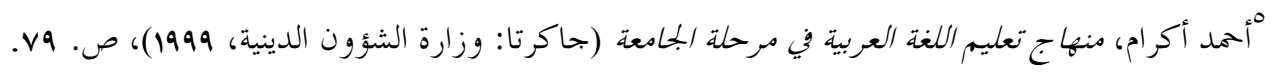


المتواصل بالمعرفة ضمن الظروف والتطورات العصرية وهذا لا يقتصر على معرفة تكنولجيا في التربية'

ومن المزايا التي ذكر أن للوسائل التعلمية لها أهمية كبيرة حيث إفا بتلب السرور للتلاميذ،

وبتحد نشاطهم، وتحبب إليهم المدرسة، وإها تصفي على الدرس حياة، بما يتطلبه استخدامها من

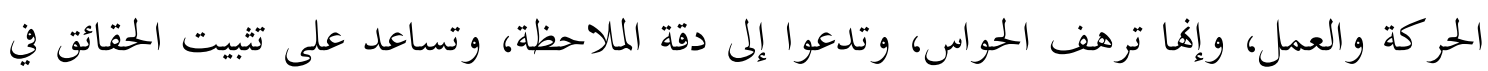

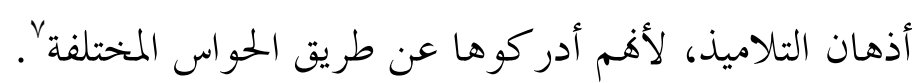

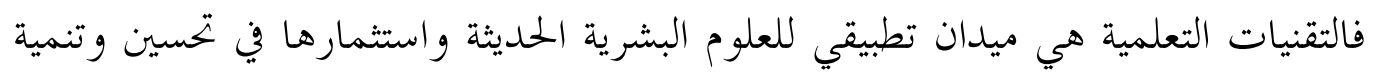
البيئة وتطويرها وتجديدها وتقويمها حتى تتحقق الأهداف التعلمية المرجوة بفاعلية و كفاءة، فمهما

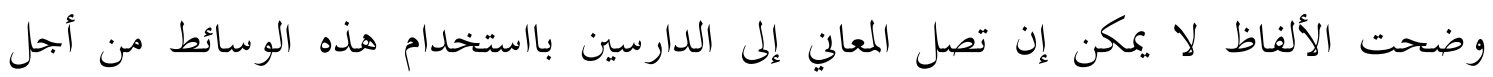
توضيحها، كما أها تزيد من القدرة على الفهم وتؤدي إلى اكتساب المهارات، وتؤدي إلى تنمية

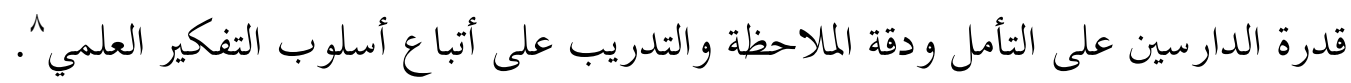

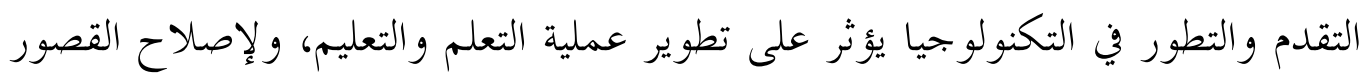
و النقائص الموجودة في بحال التربية، ومن ضمن إصلاحات في هذا البحال هو تغيير عملية التعليم من الطريقة التقلدية التي استخدمه بعض المدارس حكومة أم أهلية إلى الطريقة الحمديثة باستخدام

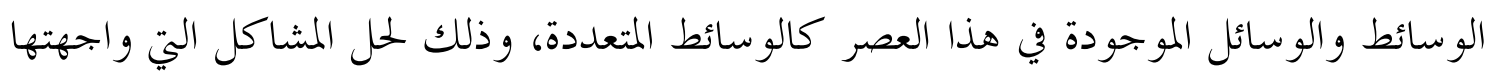
عملية التعليم.

\section{مفهوم الوسائط المتعددة}

تتكون كلمة الوسائط المتعددة من كلمة (multi)، تعني المتعددة أو المتنوعة و(media)،

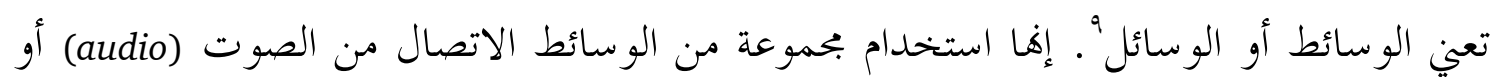
الصور (visual)، أو فيلم أو فيديو ابصورة مدبحة ومتكاملة من أجل تحقيق فعالية في عملية التعليم.

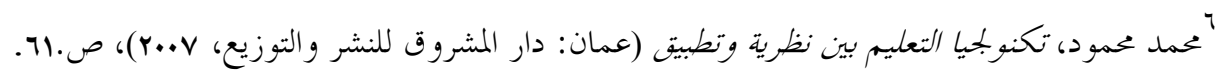

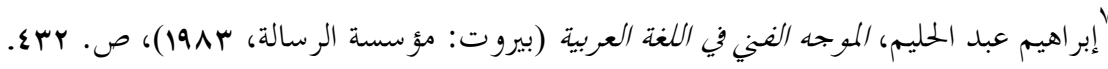

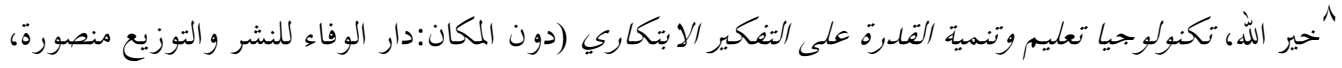

. or . 9عبد الحافظ محمد سلمة، تصميم الوسائط المتعلدة وإنتاجها (رياض: دار الخريج، دون السنة)، ص. 19.
} 
وأيضا أها خليط من عناصر موضوعة ومتكاملة، وتتكون من بحموعة وسائط الاتصال المختلفة كالنصوص، والصور، والرسوم، والأفلام.

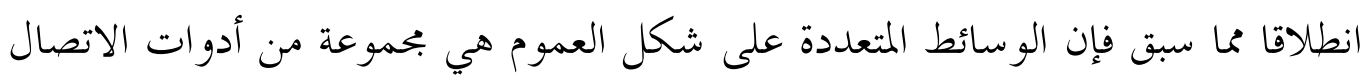


نراها حولنا في كل وقت، توضيح القصص يستخدم فيها النص والصور، ويستخدم الكارتون

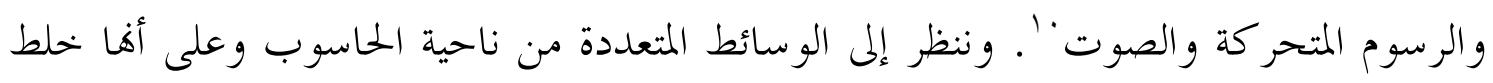

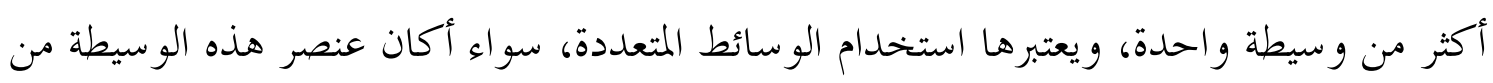
الصوت، أم الصورة، أم النص، أم الفيديوا، أم غيرها.





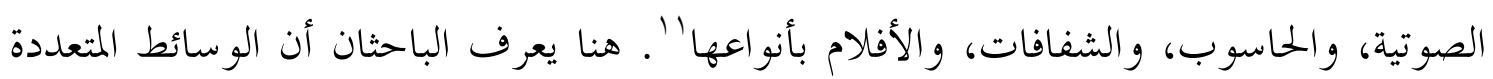



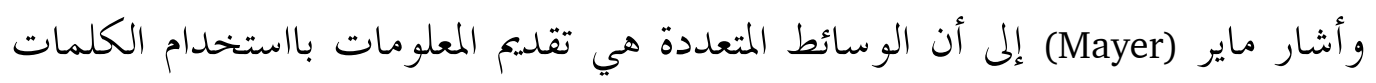

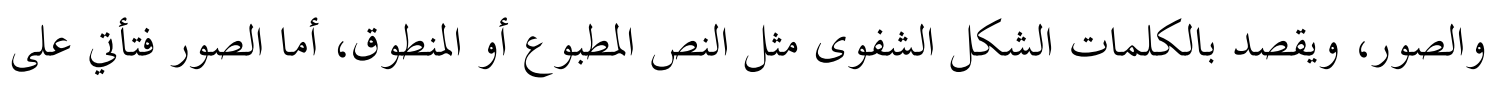




المتعددة له أشكال خاصة في تشغيل عناصرها.



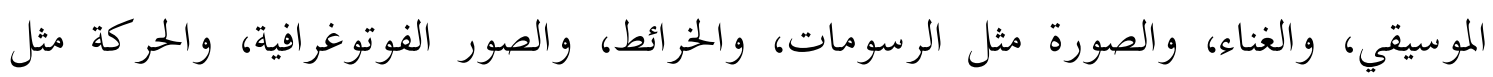



${ }^{10}$ Lach, Vivi, Making Multimedia in the Classroom: A Teacher Guide (Routledge Falmer, 2000), p. 2. "'الضبيان، صالح، منظومة الوسائط المتعددة في التعليم الرسمي: دراسة عربية، تحريز: مصطفي عبد السميع محلد



${ }^{12}$ Mayer, Richard. E, The Cambridge Handbook of Multimedia Learning (UK: Cambridge Universty Press, 2005), p. 2. 
و بشكل متتابع، ويطلب تنفيذ البرماجيات الحاسوبية التي تستخدم الوسائط المتعددة معالما سريعا،

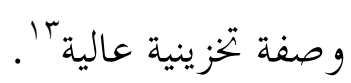

فوجود الوسائط المتعددة ليس أمرا غاليا وتدور بالأشخاص المعينة وإنما تدور جميع الناس.

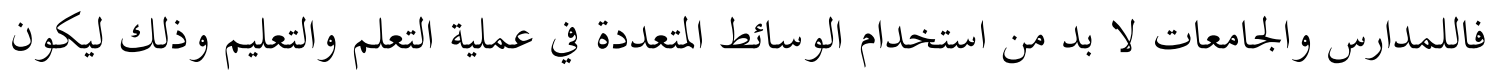
التعليم فعالة ومشوقة عند الطلبة. وتغير حضارة الإنسان تؤدى إلى تغير نظام التعليم في المدرسة.

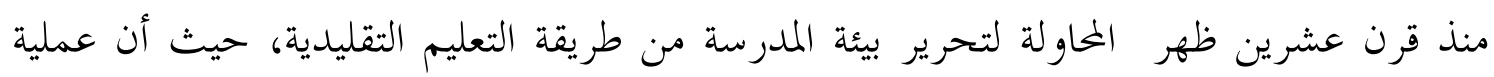
التعليم تركز وتسيطر عليه المدرس فقط حتى تكون التعليم مملة وغير مشوقة لدى الطلبة.

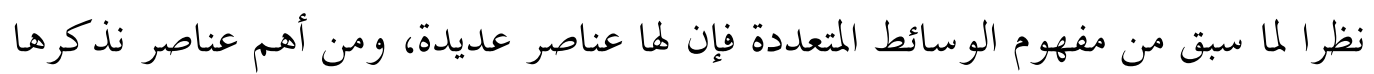
فيما يلي: النص (Teks) وهو المادة التعليمية التي تفرض على المتكلم بشكل مطبوع، ويعتبر استخدام

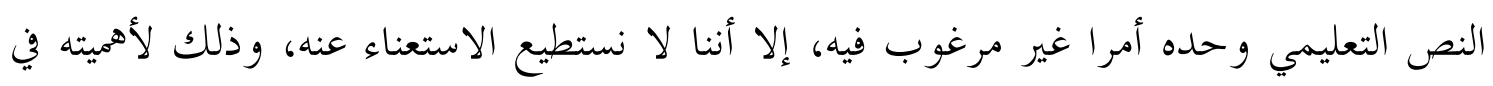



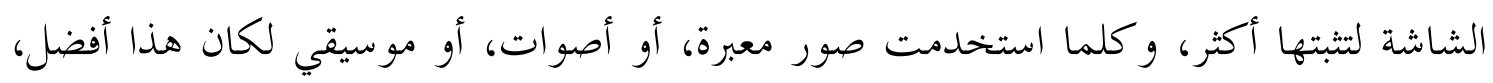

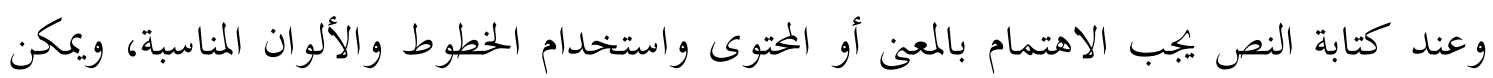

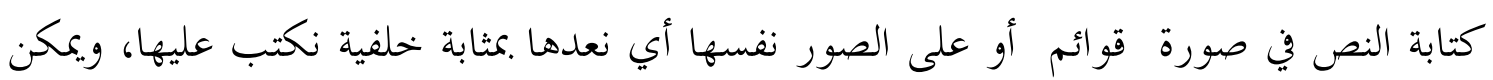

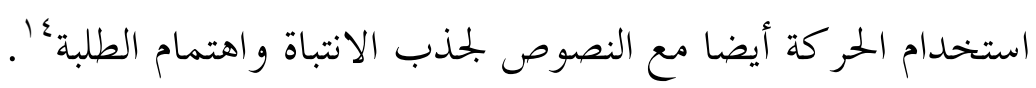

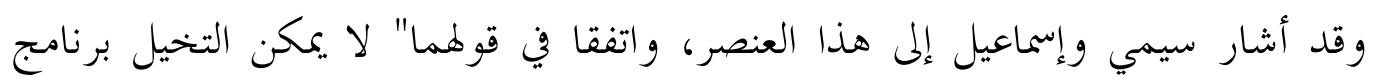

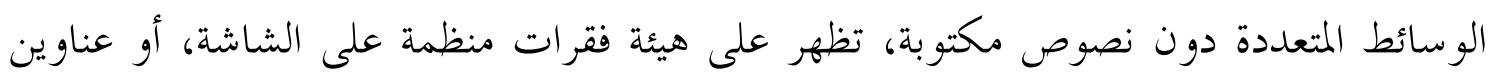

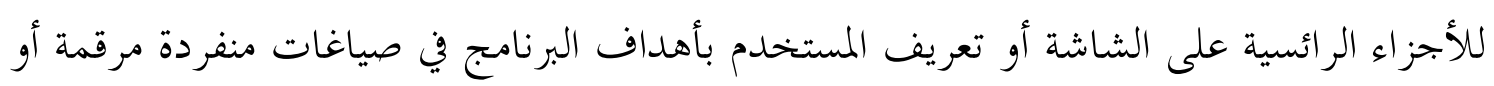



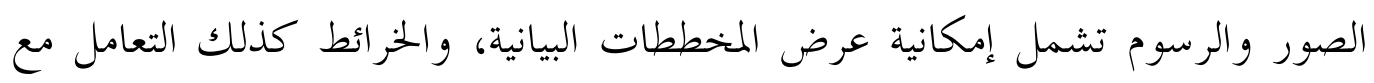
الصورة الثابتة والصور افوتوغرافية، ويتم إدخال الصور إلى الحاسب إما بالرسوم المتحركة المركة

"'ا'الفار، إبراهيم عبد الو كيل، الوسائط المتعددة التغاعلية (مصر: طنطا، دون سنة)، ص. •آץ.

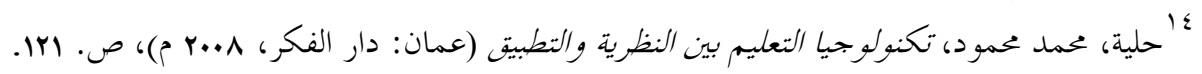

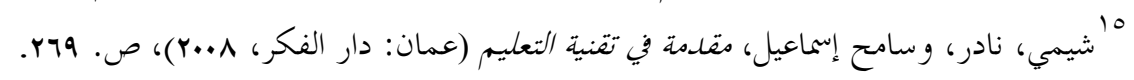


بااستقطابعا من الكاميرا الرقمية مثلا أو الماسح الضوئي أو يتم ذلك باستخدامها مع استخدام

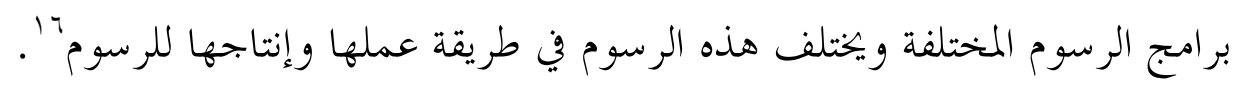

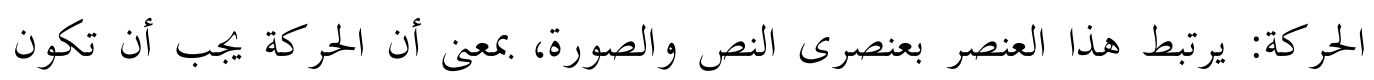

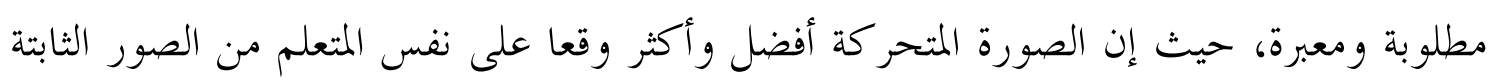

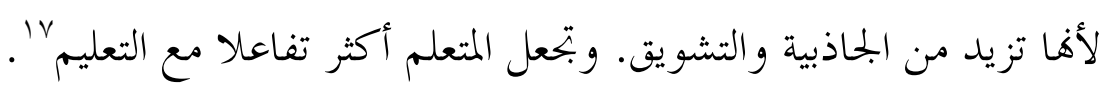

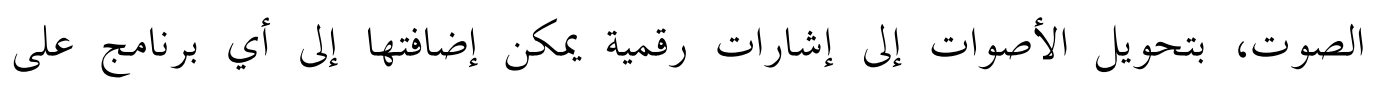

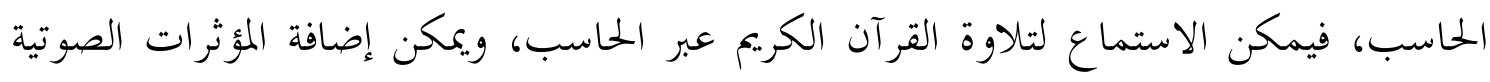

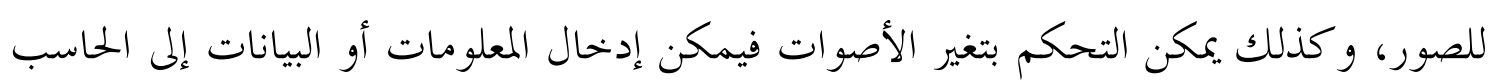

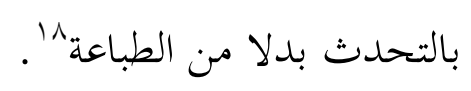
الفيديوا: يؤدي الفيديوا دورا كبيرا مهما بوصفه عنصرا من عناصر الوسائط المتعددة،

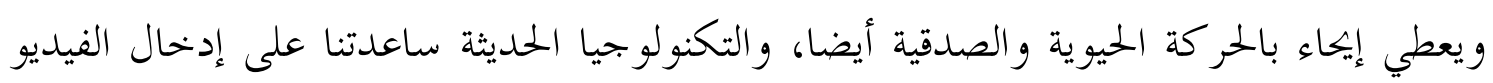

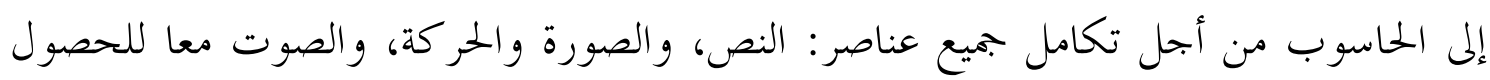

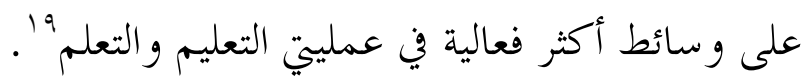

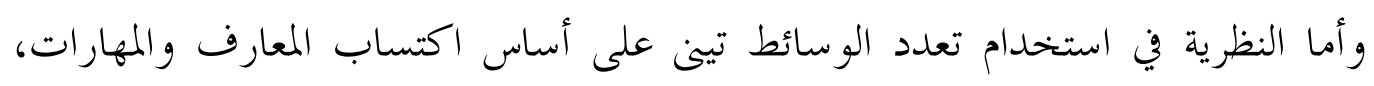

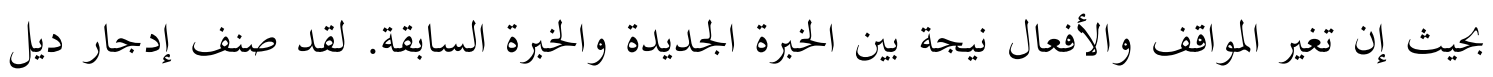

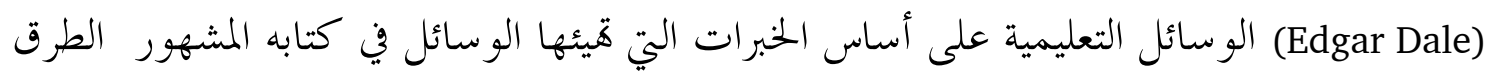

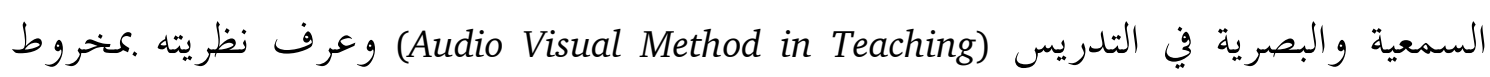
الخبرة (Dale's Cone of Experience) أن الخبرة تبدأ من الأشياء الخحسوسة إلى الأشياء الخحردة،

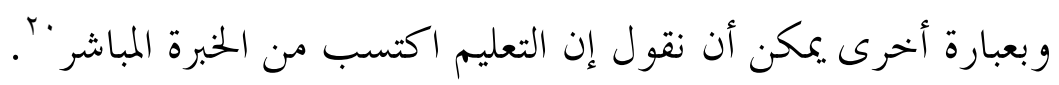

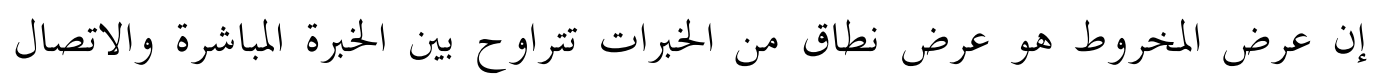



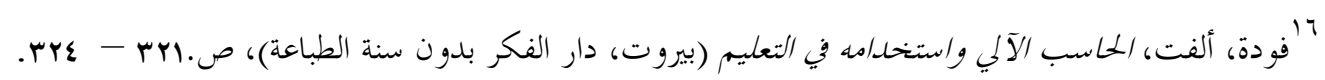

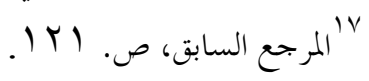

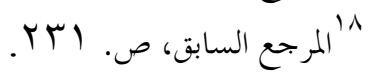

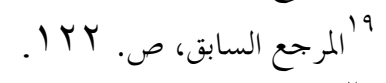

$$
\begin{aligned}
& \text { •أزهر أرشاد، الوسائل التعليمية (جاكر التا: جر افندوا برسادا، 1991 م)، ص. } 19 \text { م. }
\end{aligned}
$$


ديل (Dale) أن الرموز والأفكار البحردة يمكن أن يفهمها المتعلم ويتذكرها بسهولة أكبر إذا كانت

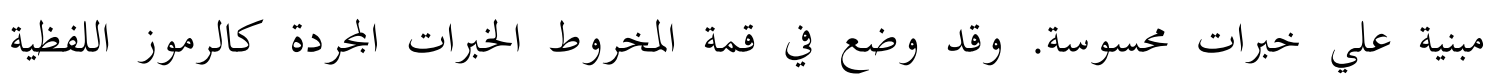
والبصرية، وفي قاعدة المخروط الخبرات الملموسة الحسبية الواقعية. وقام بترتيب الوسائل التعليمية

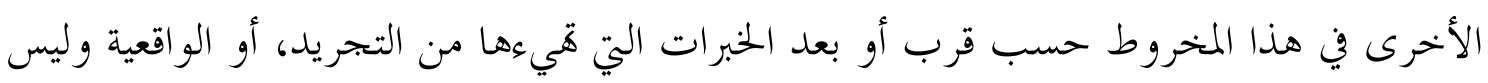

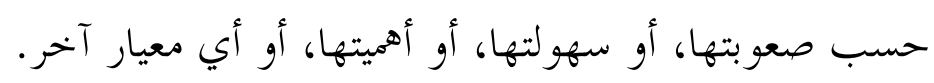

Reseach and تستخدم هذه الدراسة بالمدخل أو استراتيجيات البحث والتنمية Development

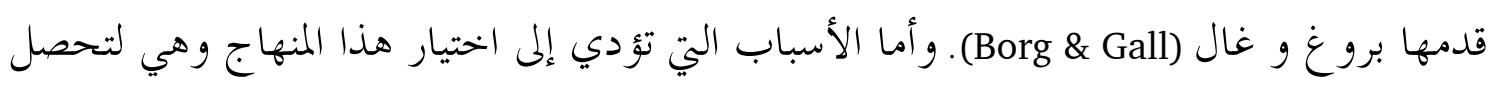

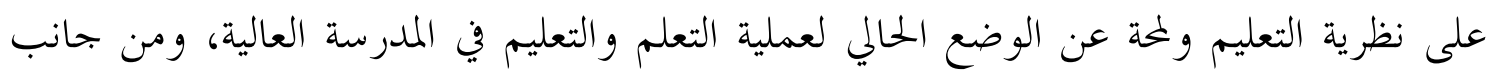

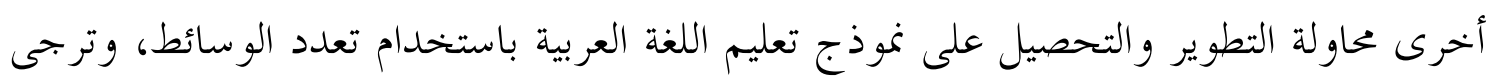





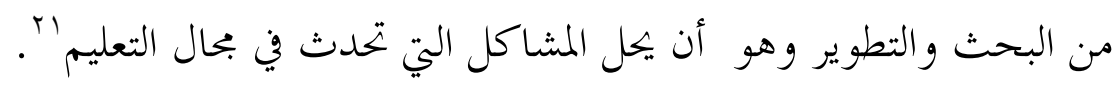



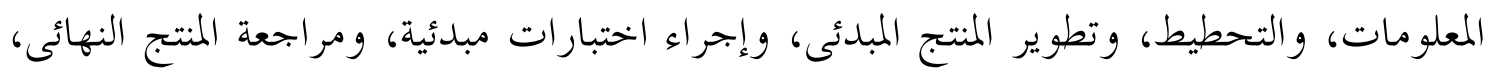

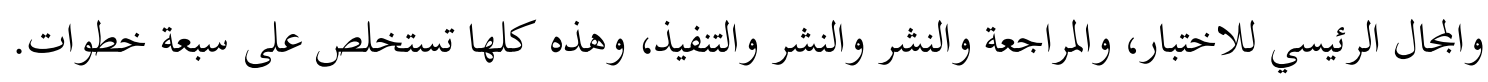

\section{تطوير النموذج}

تطوير نموذج التعليم باستخدام الوسائط المتعددة تناسب ببيئة المدرسة العالية الحكومية كاليمنتان الجنوبية، ففي هذا الفصل ستوضح الأحوال التي تتعلق بنموذج التعليم باستخدام

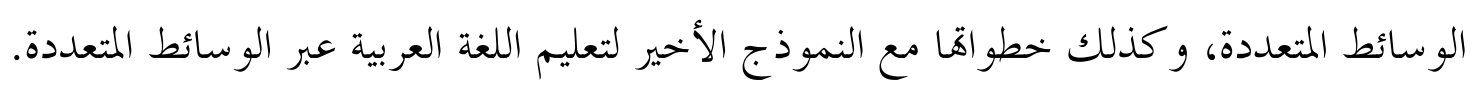

${ }^{21}$ Borg, W.R \& Gall, M.D. Gall, Educational Research: An Introduction, (New York: Longman, 1983), P. 45. 
هدف تطوير نموذج تعليم اللغة العربية باستخدام الوسائط المتعددة لترقية فعالية التعليم، وكانت فعالية التعليم هي من إحدى سمات النموذج. فنموذج التعليم المطورة لمادة اللغة العربية هدف لتصليح عملية التعلم والتعليم التي تتنص في مهارة من المهارات الأربعة ألا وهي مهارة


و كذلك مهارة الكتابة. فتطوير هذه المهارة ستؤثر على مهارة أخرى.

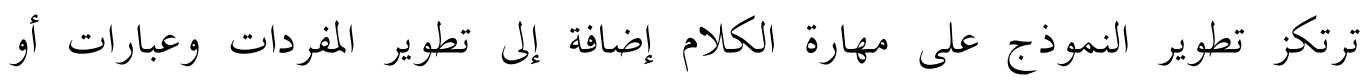

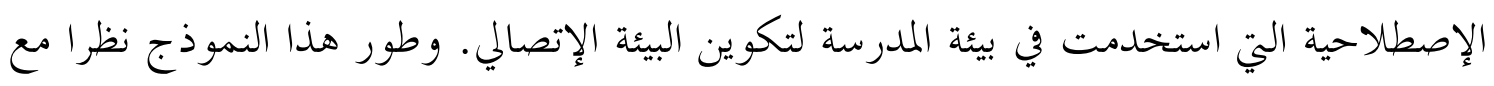





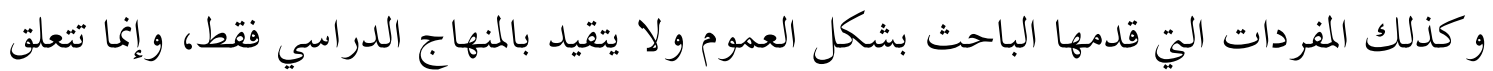
المفردات بحياهم اليومية، سواء كانت في المدرسة أم في البيت.



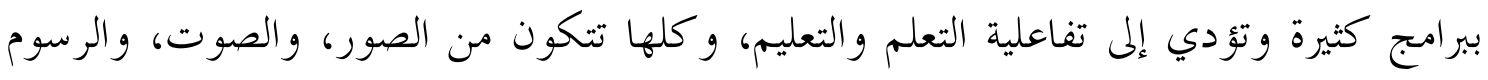

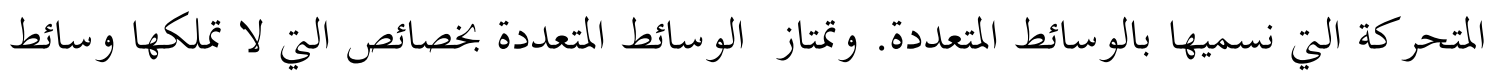

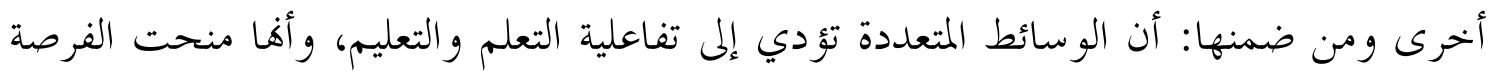

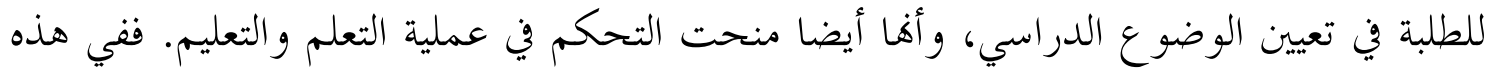

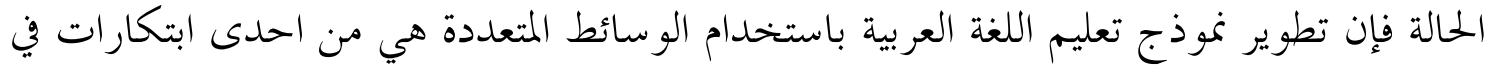
بحال التعليم وذلك لتقديم تعليم اللغة العربية بطريقة أحسن من قبلها، وكذلك لتسهيل المعلمين والمتعلمين في عملية التعلم و التعليم.

\section{خطوات تطوير النموذج}

ولتطوير نموذج التعليم، بتري الخطوات في هذا البحث ونذكره فيما يلي:

وهي دراسة المنهاج الدراسي، النظريات المناسبة بالتربية، وتعليم اللغة، وسيكولوجية التعلم، وأيضا نظريات التي تتعلق بتدريس الأدب، و تطوير الكتاب المدرسي باستخدام تعدد




المنهاج الدراسي هو من لب عملية التعلم والتعليم، وكان له أثر مباشر في النتيجية




نشاط عملية التعلم و التعليم لتحقيق الأهداف المرجوة.



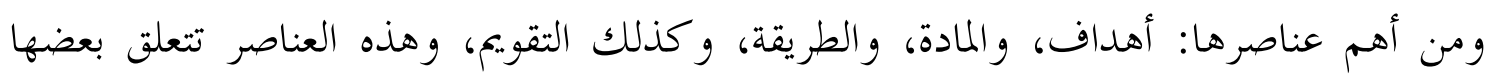



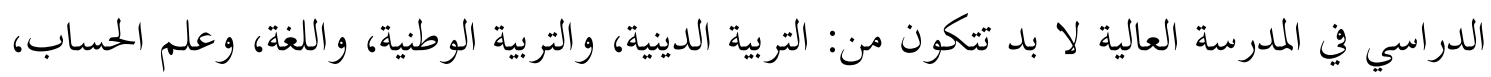
وعلم الطبيعة، وعلم الإجتماعي، وعلم الفن و الثقافة، وعلم الرياضة، و كذلك تدريب لمنيب المهارات.

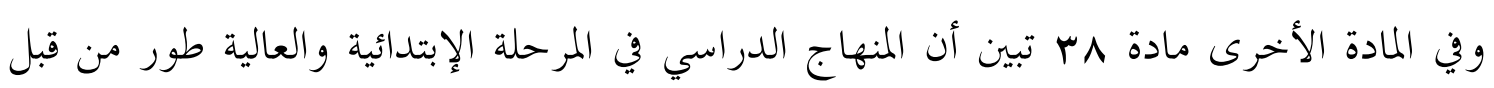



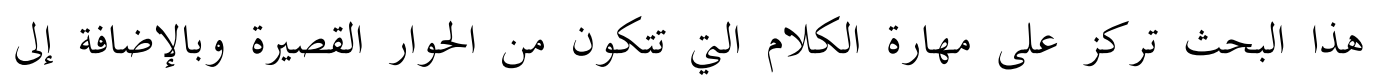

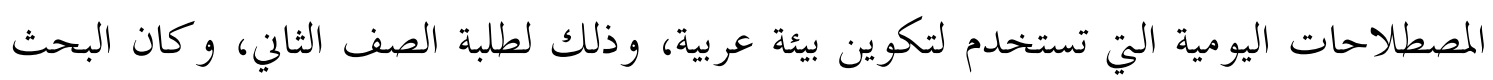

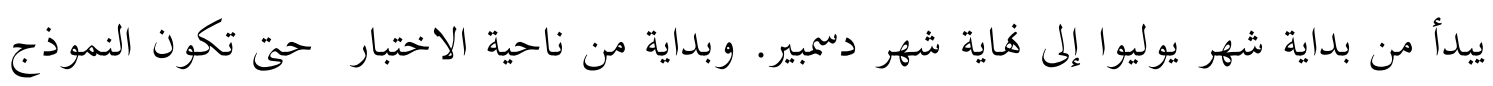

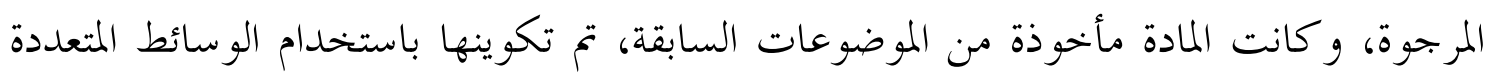

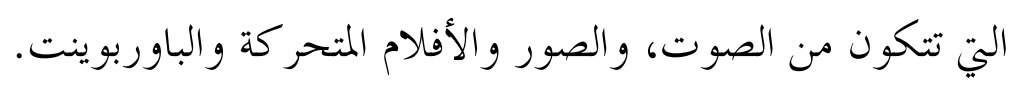

\section{تطوير مادة التعليم باستخدام الوسائط المتعددة}

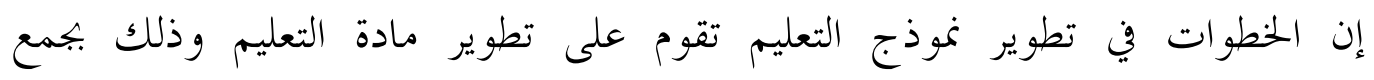

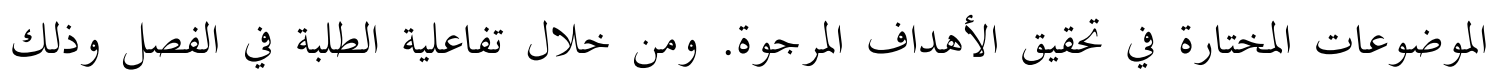

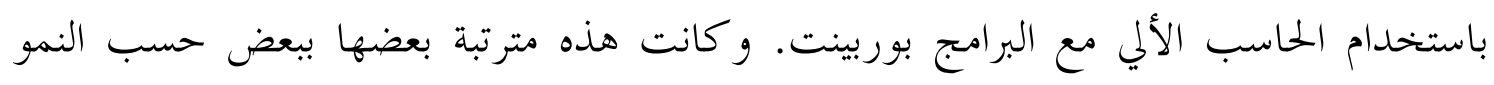



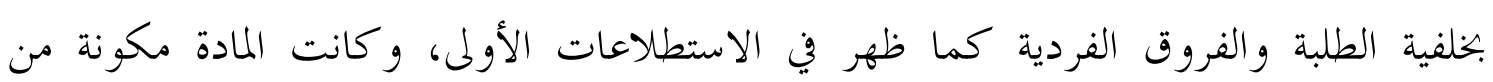
الموضوعات والمفردات والعبارات المستخدمة في البيئة المدرسية.

r "rيو ديه سو كماديناتا، تطوير المنهاح الدراسي بين النظري والتطبيقي (بندونج: رشدا كاريا، ا...r م)، ص. r.1. 
وتعامل الطلبة من خلال الحاسب الآلي والشاشة موجهة للطلبة وجهاز عرض الكريستال

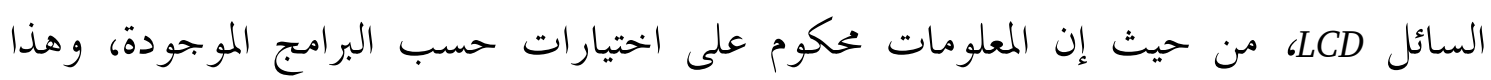

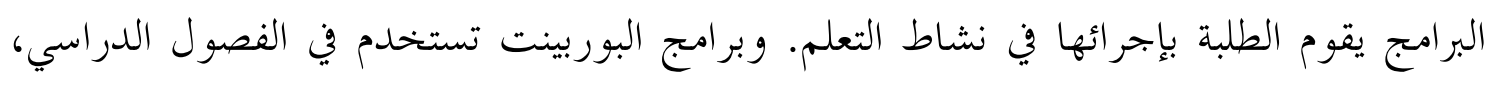

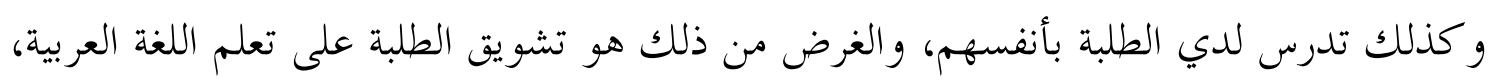

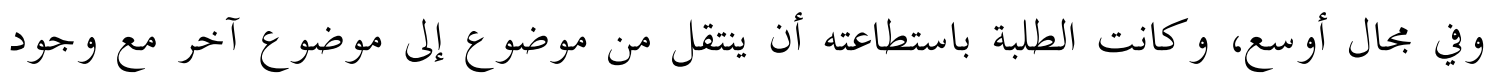
تنوع الوسائط كالصور، والأفلام، و كذلك الرسوم المتحر كة.

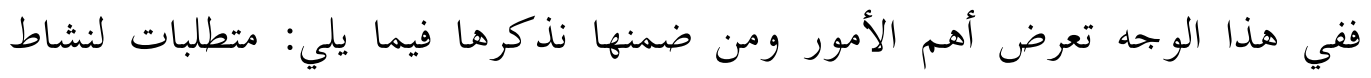

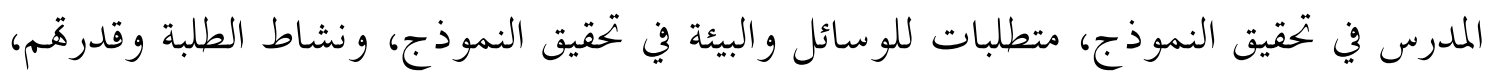
مع تصميم لنموذج التعليم.

فنموذج التعليم المطورة في هذا البحث يطلب على مهارة المدرس في تخطيط عملية التعلم



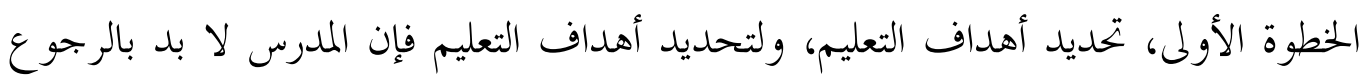

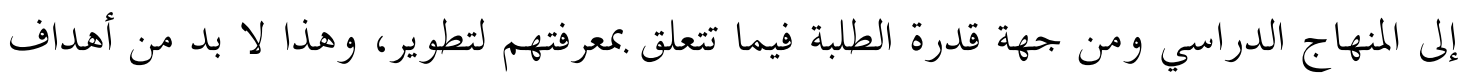

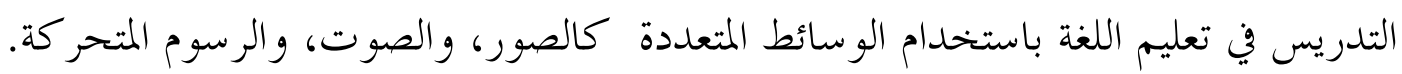

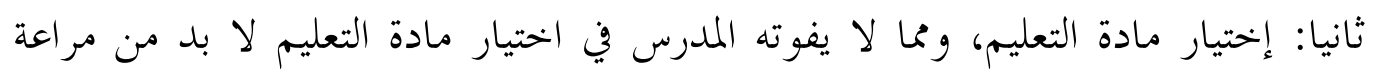

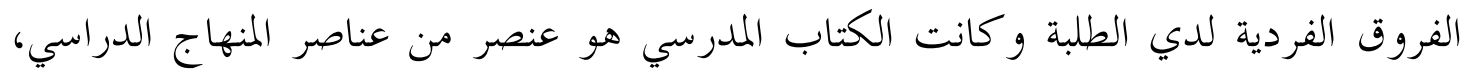
وتعتبر كالوعاء التي تمتليئها للطلبة، والمدرس هو الوسيلة في توصيل المعلومات إلى الطلبة. ثالثا، اختبار المادة للطلبة على فعالية التعليم باستخدام الوسائط المتعددة لترقية مهارة الكام لدى الطلبة، التي قام الباحث بتركيزها.

\section{المنطلبات للوسائل والبيئة في تحقيق النموذج}

للوسائل دور هام في تحقيق النموذج، حيث أن الوسائط المتعددة يحتاج إلى الآلات في

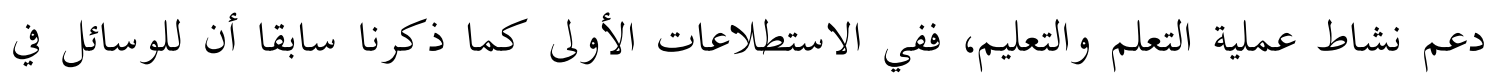

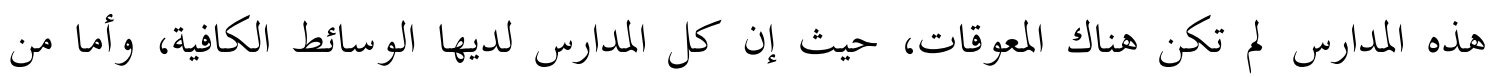
ناحية البيئة المدرسية فإن لها تعلق في نجاح إبنحاز نموذج التعليم. 
التعليم هي العملية التي دار بين المعلم والمتعلم في إبداع عملية التعلم والتعليم الجيد والفعال،





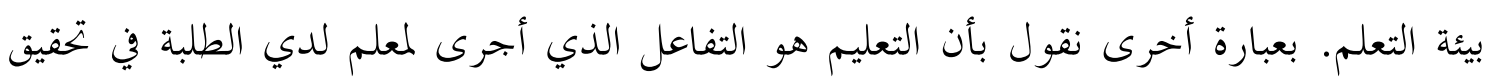

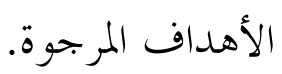

انطلاقا مما سبق فإن للمعلم له دور كبير في تخطيط وتحقيق المنهاج الدراسي، وبعبارة


المدرسي بجموعة من المعلومات فحسب وإنما هي إتحاد من المعلومات الشاملة. ففي تخطيط المادة الدراسي يقوم المعلم بتحليلها وتطوير المادة حتى تكون المفهوم العامة المطورة وذلك نظرا أن المعلم هو الذي يعرف عن أحوال التعلم والتعليم بتمامها، وبيد المعلم كانت نظرية التعليم حققت في تقديم الدروس، ومن جانب أخرى دور المعلم في تطوير المادة

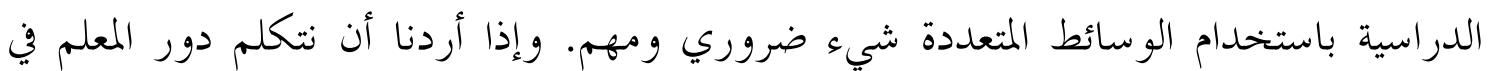
استخدام التقنية الحديثة فهناك قلق في تغيير مواقف المعلم، وهذا القلق ظهر في بداية وجود ودمد الحاسب الآلي من حيث أن وجود التقنية الحديثة ستبدل الموارد البشرية.



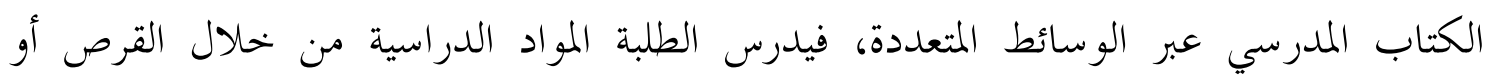

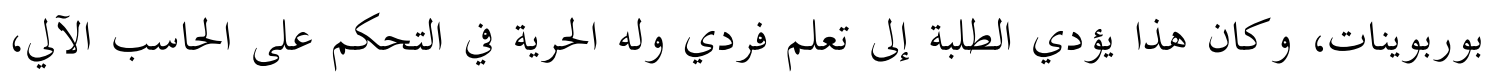

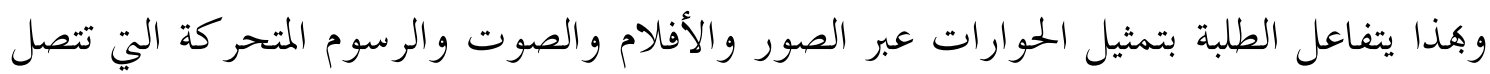
بجهاز الكريستال السائل.

فمادة دراسية هي احدى العناصر في نظام التعليم المتعلق بالمعارف، والمهارات. فمادة دراسية لها دور هام لمساعدة الطلبة في تحقيق الأهداف المرجوة. وتشعر الطلبة حاليا بصعوبة حيث




تعليم اللغة العربية. 


\section{نتيجة لتجربة النموذج}

فتصميم نموذج التعليم المطور يشتمل على: الأهداف، والمادة، والخطو ات، والتقويم، وأما الأهداف المرجوة التي هدف لتحقيق نموذج التعليم فتوجه لترقية مهارة الكلام.

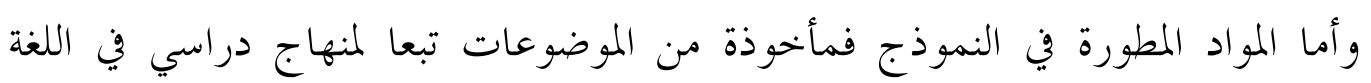



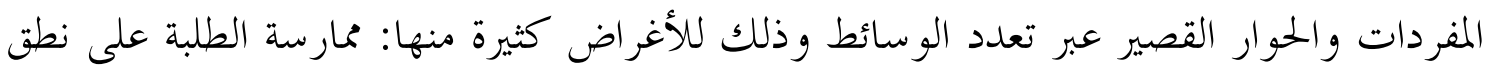


والأفلام المتحر كة، توضيح الكلمات والجمل عبر الأفلام، توضيح المعاني البحردة بالصور والأفلام.

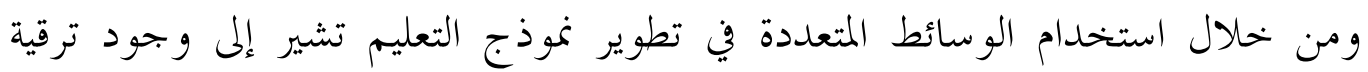

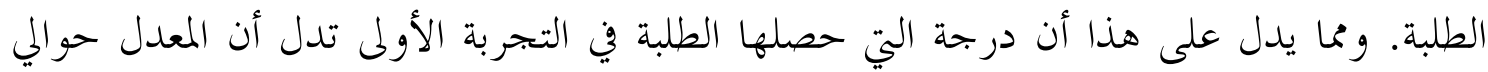

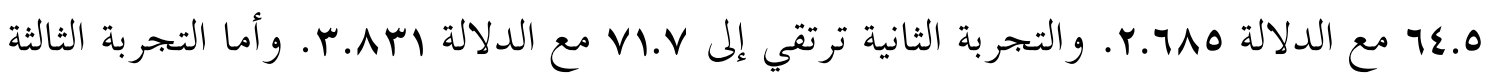

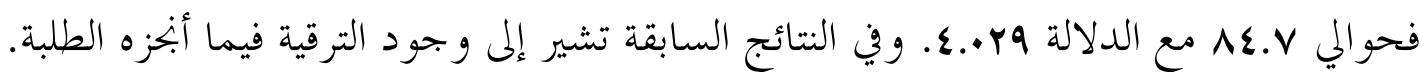
ولنعرف حول تفاعلية الطلبة في تحقيق نموذج التعليمية لترقية مهارة الطلبة على التكلم

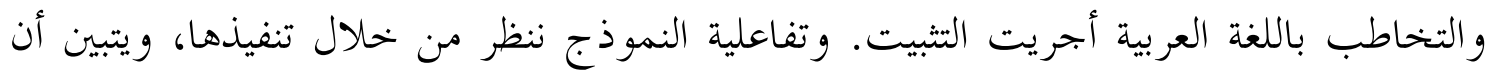
نموذج التعليم المطور في هذا البحث تشير إلى تحسين الوضع تعليم اللغة العربية.

\section{الخاتمة}

بعد ما ذكر سابقا عن الوسائط المتعددة في تطوير نموذج تعليم اللغة العربية توصلنا إلى نتائج مهمة كالتالي: تستخدم طريقة القواعد والنرجمة في تعليم اللغة العربية وذلك نظرا أن الكتاب الدراسي تبنى على أساس القواعد أو النحو، وأغلب الطلبة يقولون بعدم رغبتهم في تعلم اللغة العربية


التعليم على الأهداف المرجوة.

تصميم التعليم المطور تتكون من عدة عناصر وهي الهدف، و المادة، والطريقة، والوسيلة




من هذا القدرة على المفردات وترقية مهارة الكلام. والمادة الدراسية مكونة من بوربوينت التي

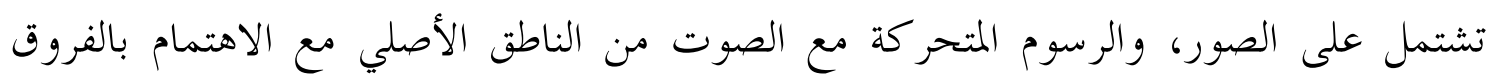

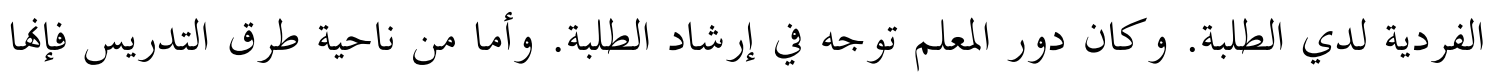

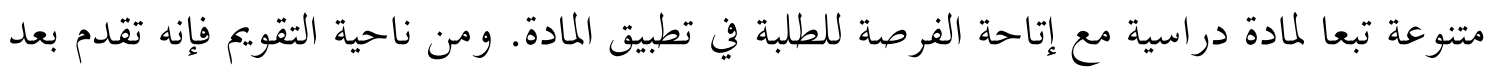
فراغ كل درس.

هناك العناصر في تحقيق نموذج تعليم اللغة العربية وهي: أولا. شرح خطوات نموذج تعليم

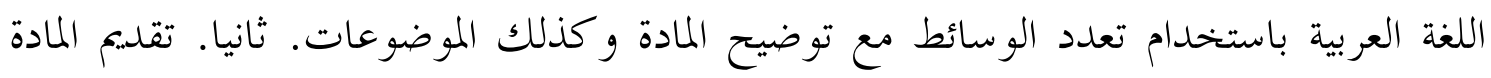

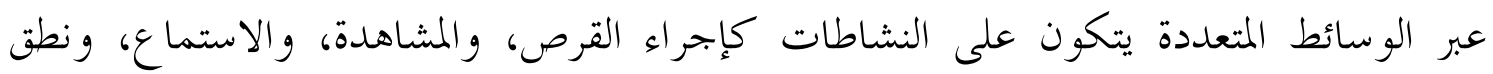
الألفاظ. ثالثا. التعمق في المادة مع إتاحة الفرصة للطلبة. رابعا. الختام التي تتكون على نتيجة

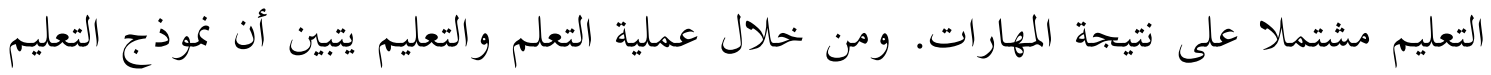

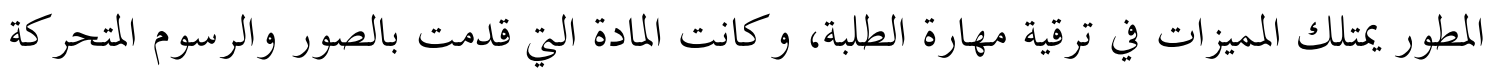
تساعد الطلبة في تذكير المفردات وتطبيقها داخل الفصل. ومن جانب آخر تشجيع الطلبة على تهلى





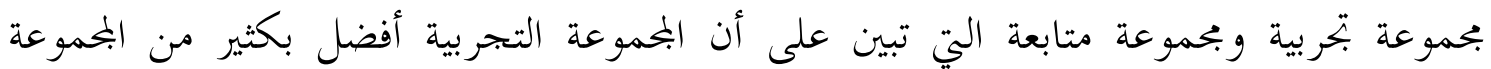

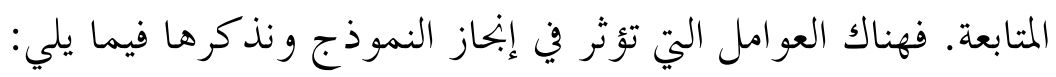



لقد تطور الزمان بحضور التقنية الحديثة وكلها تسهل في تطوير المادة باستخدام الوسائط

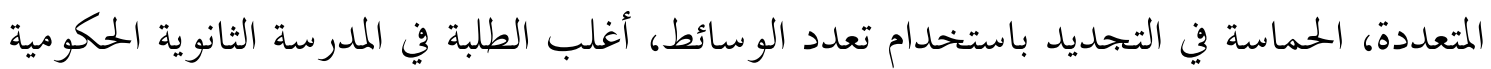

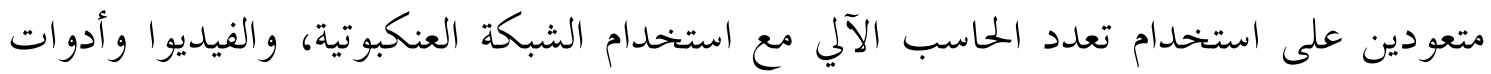
أخرى من التقنية الحديثة. المعوقات مع قلة اهتمام الباحثين في تطوير الدراسة فيما تتعلق بالتكنولوجيا التعليم، عدم وجود الغرفة البمهزة بالتقنية الحديثة في كل فصل، وقلية وقلة عدد المدرسين القادرين على استخدام التقنية الحديثة. 
أحمد أكرام. منهاج تعليم اللغة العربية في مرحلة الجامعة. جاكرتا: وزارة الشؤون الدينية، ل199 م.



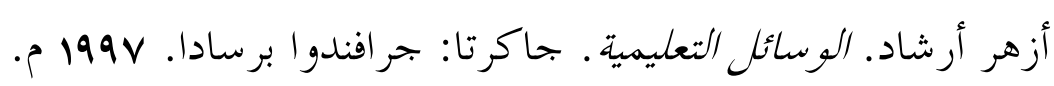


عبد الكريم. ملدى توافر مهارات تكنولوجيا التعليم لدى معلمى اللغة العربية في المرحلة الأساسية.

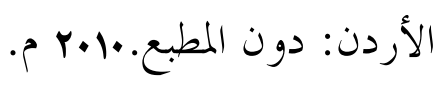

عبد الله أحمد. مذكرة في طرق تدريس اللغة العربية. الرياض المملكة العربية السعودية: جامعة مانعة محمد بن سعود. خيرالله. تكنولوجيا تعليم وتنمية القدرة على التفكير الابتكاري.منصورة: دار الوفاء للنشر والتوزيع. .01919

محمد، محمود. تكنولوجيا التعليم بين نظرية وتطبيق. عمان: دار المشيرة للنشر والتوزيع. V.. P م. سلامة. عبد الحافظ محمد. تصميم الوسائط المتعددة وإنتاجها. الرياض الملكة العربية السعودية:

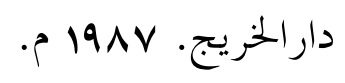
سيوديه سو كماديناتا. تطوير المنهاح الدراسي بين النظري والتطبيقي. بندونج: رشدا كاريا. ا..ب م.

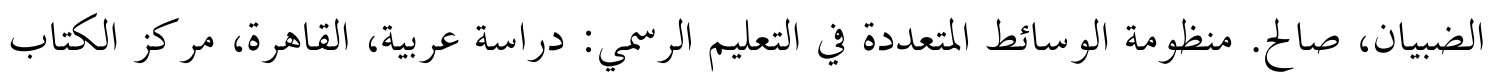
للنشر. 1999 م.

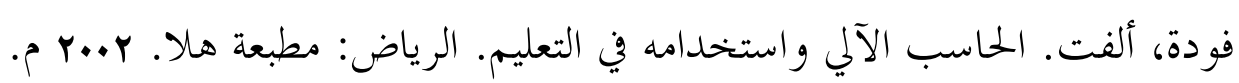



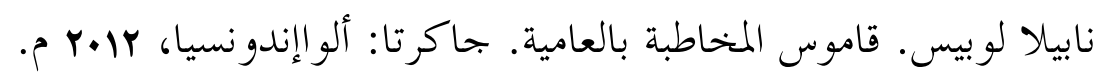
Lach, Vivi. Making Multimedia in the Classroom: A Teacher Guide. Routlede Falmer, 2000. Mayer, Richard. E. The Cambridge Handbook of Multimedia Learning. UK: Cambridge University Press, 2005.

Borg, W.R \& Gall, M.D. Educational Research: An Introduction. New York: Longman, 1983. 